\title{
A frameshift polymorphism in $P 2 X 5$ elicits an allogeneic cytotoxic T lymphocyte response associated with remission of chronic myeloid leukemia
}

\author{
Björn de Rijke,1 Agnes van Horssen-Zoetbrood,1 Jeffrey M. Beekman,1 \\ Britt Otterud,, ${ }^{2}$ Frans Maas, ${ }^{1}$ Rob Woestenenk, ${ }^{1}$ Michel Kester, ${ }^{3}$ Mark Leppert, ${ }^{2}$ \\ Anton V. Schattenberg, ${ }^{4}$ Theo de Witte ${ }^{4}$ Elly van de Wiel-van Kemenade, ${ }^{1}$ and Harry Dolstra ${ }^{1}$ \\ ${ }^{1}$ Central Hematology Laboratory, Nijmegen Centre for Molecular Life Sciences, Radboud University Nijmegen Medical Centre, \\ Nijmegen, The Netherlands. ${ }^{2}$ Department of Human Genetics, University of Utah, Salt Lake City, Utah, USA. \\ ${ }^{3}$ Department of Hematology, Leiden University Medical Center, Leiden, The Netherlands. ${ }^{4}$ Department of Hematology, \\ Nijmegen Centre for Molecular Life Sciences, Radboud University Nijmegen Medical Centre, Nijmegen, The Netherlands.
}

\begin{abstract}
Minor histocompatibility antigens (mHAgs) constitute the targets of the graft-versus-leukemia response after HLA-identical allogeneic stem cell transplantation. Here, we have used genetic linkage analysis to identify a novel mHAg, designated lymphoid-restricted histocompatibility antigen-1 (LRH-1), which is encoded by the $P 2 X 5$ gene and elicited an allogeneic CTL response in a patient with chronic myeloid leukemia after donor lymphocyte infusion. We demonstrate that immunogenicity for LRH-1 is due to differential protein expression in recipient and donor cells as a consequence of a homozygous frameshift polymorphism in the donor. Tetramer analysis showed that emergence of $\mathrm{LRH}-1-$ specific $\mathrm{CD8}^{+}$cytotoxic $\mathrm{T}$ cells in peripheral blood and bone marrow correlated with complete remission of chronic myeloid leukemia. Furthermore, the restricted expression of LRH-1 in hematopoietic cells including leukemic $\mathrm{CD}_{3} 4^{+}$progenitor cells provides evidence of a role for $\mathrm{LRH}-1-$-specific $\mathrm{CD8}^{+}$cytotoxic $\mathrm{T}$ cells in selective graft-versus-leukemia reactivity in the absence of severe graft-versus-host disease. These findings illustrate that the $P 2 X 5$-encoded mHAg LRH-1 could be an attractive target for specific immunotherapy to treat hematological malignancies recurring after allogeneic stem cell transplantation.
\end{abstract}

\section{Introduction}

HLA-identical allogeneic hematopoietic stem cell transplantation (SCT) is a curative therapy for various forms of hematological malignancies (1). It has become the treatment of choice for patients with chronic myeloid leukemia (CML) and is currently the most effective consolidation treatment for patients with acute leukemia $(2,3)$. The therapeutic efficacy is attributed to the graftversus-leukemia $(G V L)$ reaction, an immune response in which donor-derived CTLs eliminate malignant cells of the recipient (4, 5). Minor histocompatibility antigens (mHAgs) are the target antigens of the GVL response, and expansion of $\mathrm{mHAg}$-specific CTLs has been shown to precede clinical remission in relapsed CML patients treated with donor lymphocyte infusions (DLIs) $(6,7)$. However, alloreactive CTL responses induced upon DLI generally lack tumor specificity and are often accompanied by graft-versushost disease (GVHD). Selective GVL responses in the absence of GVHD may result from $\mathrm{mHAgs}$ with expression limited to hematopoietic cells such as HA-1 (8), HA-2 $(9,10)$, and BCL2A1 (11) or

Nonstandard abbreviations used: $\mathrm{CEPH}$, Centre d'Etude du Polymorphism Humain; CML, chronic myeloid leukemia; CsA, cyclosporin A; DLI, donor lymphocyte infusion; GVHD, graft-versus-host disease; GVL, graft-versus-leukemia; IMDM, Iscove's modified Dulbecco's medium; LCL, lymphoblastoid cell line; lod, log odds ratio; LRH-1, lymphoid-restricted histocompatibility antigen-1; mHAg, minor histocompatibility antigen; PHA, phytohemagglutinin; SCT, stem cell transplantation. Conflict of interest: The authors have declared that no conflict of interest exists.

Citation for this article: J. Clin. Invest. 115:3506-3516 (2005).

doi:10.1172/JCI24832. to lineage-specific hematopoietic cells such as HB-1 $(12,13)$. These hematopoietic cell-restricted antigens represent potential targets for specific immunotherapy after allogeneic SCT (14-16).

mHAgs are HLA-bound peptides derived from cellular proteins that differ in amino acid sequence between donor and recipient due to genetic polymorphisms (4, 17-19). Thus far, approximately 15 human mHAgs have been identified through mass spectrometry of HLA-eluted peptides $(8,9,20-24)$, cDNA library cloning $(13,25)$, or genetic linkage analysis $(11)$. Immunogenicity of most of the molecularly characterized human mHAgs results from single nucleotide polymorphisms (SNPs) in homologous donor and recipient genes causing amino acid substitutions within the epitope (8-11, 13, 20-24). In 1 instance, an mHAg encoded by the UGT2B17 gene resulted from differential protein expression in donor and recipient cells as a consequence of a homozygous gene deletion in the donor (25).

Here, we report the identification of a novel hematopoietic cellrestricted $\mathrm{mHAg}$, designated lymphoid-restricted histocompatibility antigen-1 (LRH-1), which elicited an HLA-B7-restricted CTL response in a CML patient treated with DLI. Using genetic linkage analysis and gene profiling, we have identified $P 2 X 5$ as the polymorphic gene encoding the LRH-1 antigenic peptide. Our data provide what we believe to be the first evidence that mHAg disparity can result from differential protein expression due to a homozygous frameshift polymorphism. Furthermore, we have analyzed the kinetics of the LRH-1-specific CTL response in the CML patient and show that emergence of LRH-1/B7 
A

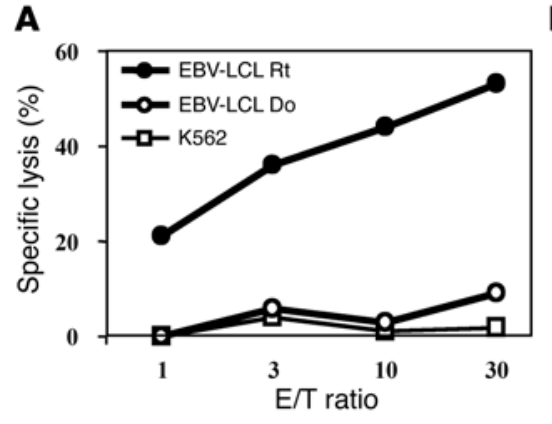

C

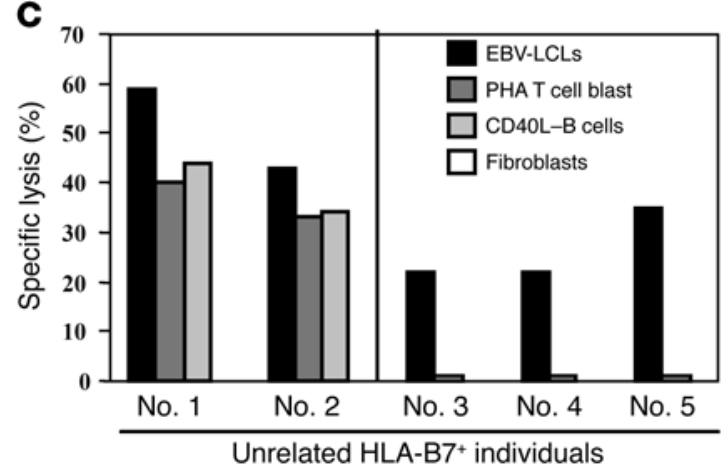

B Stimulator cells

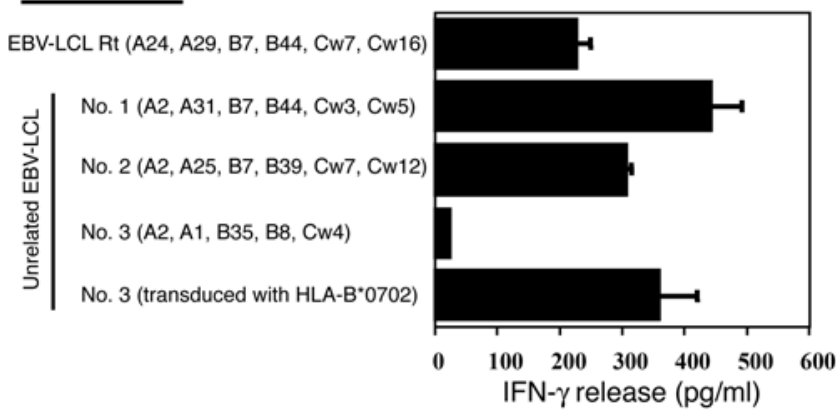

D

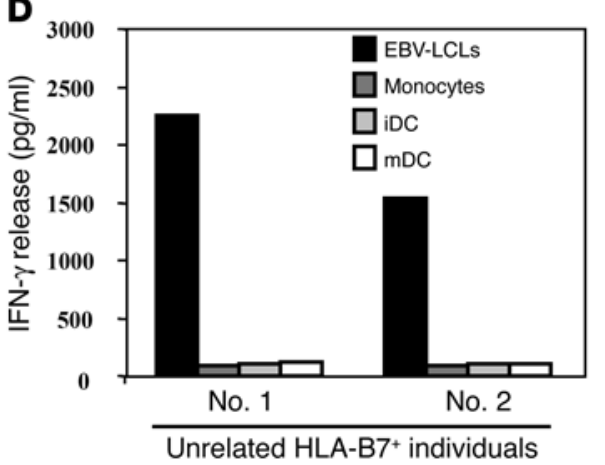

Figure 1

Specific reactivity of $\mathrm{HLA}-\mathrm{B}^{\star} 0702-$ restricted CTL RP1 against hematopoietic cells. (A) Specific cytotoxicity was tested in ${ }^{51} \mathrm{Cr}$ release assays against EBV-LCLs of the recipient (Rt) and donor (Do). NK-sensitive K562 cells were used to determine nonspecific lysis. Effector to target (E/T) ratios are indicated. (B) Production of IFN- $\gamma$ by CTL RP1 stimulated with recipient EBV-LCLs, EBV-LCLs of 2 unrelated individuals (nos. 1 and 2 ) sharing HLA-B7 with the recipient, and an EBV-LCL of an HLA class I-mismatched individual (no. 3) that was transduced with HLA-B*0702. Data are displayed as mean IFN- $\gamma$ release \pm SD of triplicate wells. (C) Specific cytotoxicity against hematopoietic cells of lymphoid origin (EBV-LCLs, PHA-stimulated T cells, and CD40L-stimulated B cells) and BM-derived fibroblasts incubated with $10 \mathrm{ng} / \mathrm{ml}$ TNF- $\alpha$ and $100 \mathrm{U} / \mathrm{ml}$ IFN- $\gamma$ for 2 days before ${ }^{51} \mathrm{Cr}$ labeling. The E/T ratio was $1: 1$. (D) IFN- $\gamma$ production by CTL RP1 upon stimulation with hematopoietic cells of myeloid origin (monocytes, immature DCs [iDC] and mature DCs [mDC]).

tetramer ${ }^{+} \mathrm{T}$ cells is associated with GVL reactivity following DLI. Finally, our observation that LRH-1 is selectively expressed within the hematopoietic system including leukemic CD $34^{+}$progenitor cells offers a novel target antigen for the development of immunotherapy for the treatment of relapsed leukemia.

\section{Results}

Case description. In 1996, we transplanted a marrow graft into a 35-year-old woman (UPN389) with Philadelphia chromosomepositive $\left(\mathrm{Ph}^{+}\right) \mathrm{CML}$ from her HLA-identical brother (A24, A29, B7, B44, Cw7, Cw16) after receiving informed consent. Partial T cell depletion was performed using counterflow centrifugation, and $0.8 \times 10^{6} \mathrm{CD}^{+}$cells $/ \mathrm{kg}$ body weight were given within the graft (26). The patient suffered from acute GVHD grade III (skin and liver), which was successfully treated with the addition of corticosteroids. At 6 months after SCT, FISH analysis of a BM aspirate showed 7.5\% $\mathrm{Ph}^{+}$cells. Cyclosporin A (CsA) and corticosteroids were gradually withdrawn within 2 months without reactivation of GVHD. However, 1 month after cessation of immunosuppressive treatment, $\mathrm{Ph}^{+}$cells increased to $85 \%$ in the BM. Furthermore, these cells had additional chromosomal abnormalities with del(13) and $t(4 ; 11)$, and the patient had progressed to accelerated phase. The patient was given lymphocytes from the original BM donor (DLI-1; $0.1 \times 10^{8} \mathrm{CD}^{+}$cells $/ \mathrm{kg}$ body weight) but did not respond. After a second and higher dose of DLI (DLI-2; $0.7 \times 10^{8} \mathrm{CD}^{+}$ cells/kg body weight), the patient developed GVHD of the skin and pancytopenia. For GVHD of the skin, she was treated with CsA and mycophenolate mofetil for different intervals. Six months after DLI-2, BM cells were of donor origin. Since the patient had become and remained pancytopenic, she was given a T cell-depleted marrow booster from her donor. Nine months after DLI-2 and 2 months after the stem cell booster, the patient was in complete cytogenetic and molecular remission.

CTL RP1 recognizes an HLA-B7-restricted $m H A$ Ag expressed on hematopoietic cells. To isolate $\mathrm{mHAg}$-specific $\mathrm{CD}^{+} \mathrm{T}$ cells involved in the GVL response in CML patient UPN389, we stimulated PBMCs obtained 3 months after DLI- 2 with CML cells obtained at hematological relapse. After multiple stimulations, TCR repertoire analysis revealed that more than $90 \%$ of CD ${ }^{+}$T cells expressed a clonal TCR-BV21.3 chain (data not shown). This CD8 ${ }^{+}$CTL clone, termed RP1, mediated specific lysis against the EBV-lymphoblastoid cell line (EBV-LCL) of the recipient, but not against donor EBV-LCL and NK-sensitive K562 cells (Figure 1A). Specific lysis of recipient EBV-LCL was substantially inhibited by anti-HLA class I and anti-HLA-B/C Abs, but not by Ab against anti-HLA class II, indicating recognition of an HLA class Irestricted $\mathrm{mHAg}$ (data not shown). Testing of EBV-LCLs from unrelated individuals sharing expression of HLA-B7 with the recipient and EBV-LCL from an HLA class I-mismatched individual that were transduced with HLA-B*0702 revealed that CTL RP1 recognizes an mHAg presented by HLA-B7 (Figure 1B). 
A

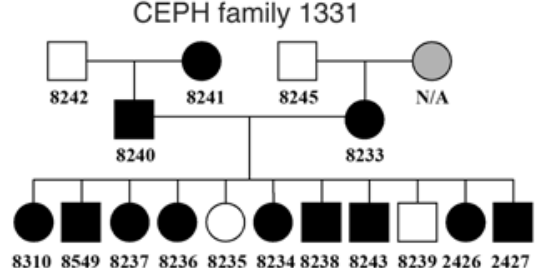

83108549823782368235823482388243823924262427 CEPH family 1332

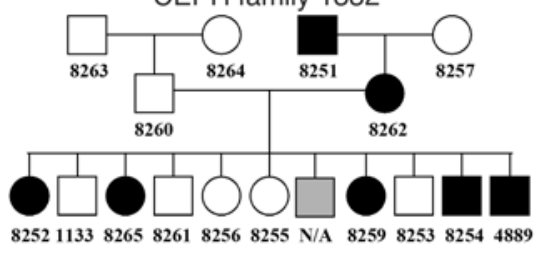

CEPH family 1347

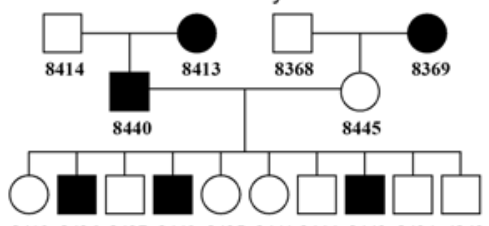

8412843684378442843584418444844384344843
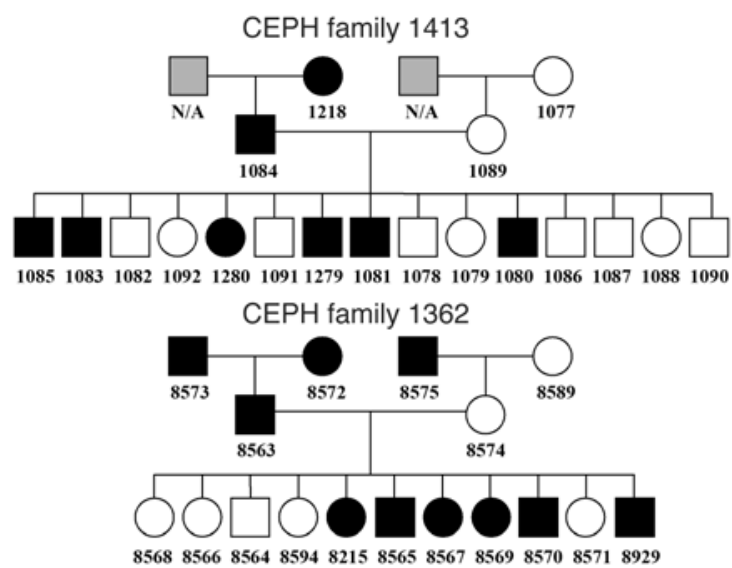

CEPH family 102

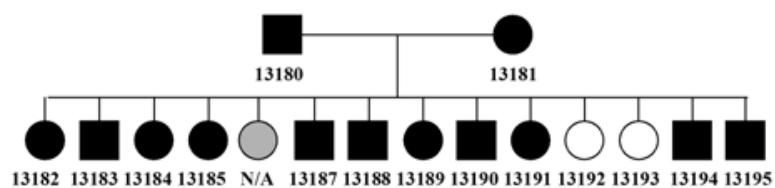

B

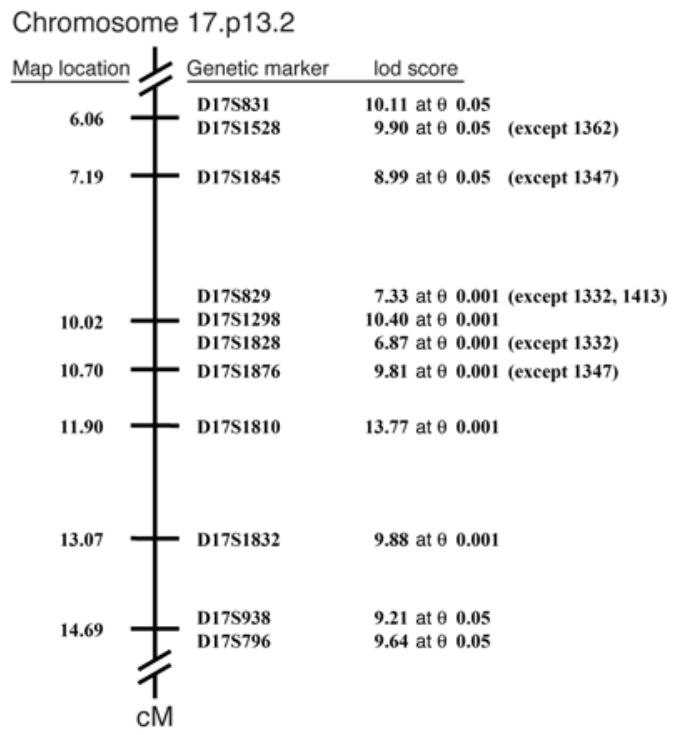

Figure 2

The LRH-1 locus is closely linked to a cluster of markers on chromosome 17p13.2. (A) LRH-1 segregation pattern for individuals of the CEPH pedigrees $1331,1332,1347,1413,1362$, and 102. EBV-LCLs of all available family members were transduced with HLA-B*0702 and tested for recognition by CTL RP1. Filled circles (females) or squares (males) represent individuals scored as positive for the LRH-1 phenotype, and open circles (females) or squares (males) represent individuals scored as negative. Shaded symbols represent individuals from whom no EBV-LCLs was available. (B) Genetic map of chromosome 17p13.2 showing relative marker loci oriented with the centromere at the bottom of the figure. lod scores summed for all available families used in the linkage analysis are shown to the right of each genomic marker. CEPH families that are not genotyped for a particular marker and therefore not included in the linkage analysis are indicated in parentheses.

Next we investigated whether the mHAg recognized by CTL RP1 was selectively expressed by hematopoietic cells. CTL RP1 significantly lysed cells of lymphoid origin such as EBV-LCLs, CD40activated B cells, and phytohemagglutinin-stimulated (PHAstimulated) T cells, whereas monocytes and monocyte-derived DCs were not recognized (Figure 1, C and D). Furthermore, no cytotoxicity of CTL RP1 was observed against TNF- $\alpha-$ and IFN- $\gamma-$ pretreated BM-derived fibroblasts (Figure 1C). By contrast, all target cell types were significantly recognized by the allo-HLA-B7- specific CTL KOR18, indicating their susceptibility to CTL-mediated recognition (data not shown). Together these data indicate that CTL RP1 recognizes an HLA-B7-restricted mHAg that is expressed by hematopoietic cells of the lymphoid lineage. Based on this CTL recognition pattern, we provisionally designated this novel mHAg as LRH-1.

The gene encoding LRH-1 is mapped to a 1.64-Mb region on chromosome 17p13.2. We performed genetic linkage analysis to map the chromosomal region containing the LRH-1-encoding gene. EBV-LCLs 


\section{Table 1}

Haplotypes of the parental probands and their informative offspring who had a recombination between the markers D17S831 and D17S796

\begin{tabular}{|c|c|c|c|c|c|c|c|c|c|c|c|c|c|c|c|c|c|c|c|}
\hline \multirow{3}{*}{$\begin{array}{l}\text { Genomic } \\
\text { markerB } \\
\text { D17S831 }\end{array}$} & \multirow{3}{*}{$\begin{array}{c}\text { Position } \\
\text { (bp) } \\
2116991\end{array}$} & \multicolumn{6}{|c|}{ Family102 } & \multicolumn{6}{|c|}{ Family 1332} & \multicolumn{6}{|c|}{ Family 1362} \\
\hline & & \multicolumn{2}{|c|}{$\begin{array}{l}\text { Father } \\
\text { (13180) }\end{array}$} & \multicolumn{2}{|c|}{$\begin{array}{l}\text { Mother } \\
\text { (13181) }\end{array}$} & \multicolumn{2}{|c|}{$\begin{array}{l}\text { Child } \\
\text { (13182) }\end{array}$} & \multicolumn{2}{|c|}{$\begin{array}{l}\text { Father } \\
(8260)\end{array}$} & \multicolumn{2}{|c|}{$\begin{array}{l}\text { Mother } \\
(8262)\end{array}$} & \multicolumn{2}{|c|}{$\begin{array}{l}\text { Child } \\
\text { (4889) }\end{array}$} & \multicolumn{2}{|c|}{$\begin{array}{l}\text { Father } \\
(8563)\end{array}$} & \multicolumn{2}{|c|}{$\begin{array}{l}\text { Mother } \\
(8574)\end{array}$} & \multicolumn{2}{|c|}{$\begin{array}{l}\text { Child } \\
(8564)\end{array}$} \\
\hline & & 6 & 2 & 7 & 1 & 6 & 7 & 6 & 2 & 8 & 1 & 6 & 1 & 3 & 1 & 6 & 2 & 3 & 2 \\
\hline D17S1528 & 2231368 & 1 & 2 & 2 & 3 & 1 & 2 & 5 & 2 & 2 & 8 & 5 & 8 & 3 & 3 & 2 & 2 & 3 & 2 \\
\hline D17S1845 & 2911459 & 4 & 2 & 6 & 1 & 4 & 6 & 8 & 5 & 9 & 10 & 8 & 10 & 5 & 3 & 4 & 3 & 5 & 3 \\
\hline D17S126 & 3268519 & 1 & 1 & 1 & 2 & 1 & 1 & 1 & 1 & 1 & 1 & 1 & 1 & 2 & 1 & 2 & 1 & 1 & 1 \\
\hline D17S1152 & 3509013 & 0 & 0 & 0 & 0 & 0 & 0 & 4 & 2 & 4 & 4 & 4 & 4 & 1 & 5 & 5 & 3 & 5 & 3 \\
\hline D17S829 & 3751859 & 3 & 4 & 4 & 4 & 3 & 4 & 2 & 2 & 3 & 3 & 2 & 3 & 5 & 4 & 3 & 6 & 4 & 6 \\
\hline D17S1298 & 3873140 & 1 & 1 & 3 & 1 & 1 & 3 & 1 & 3 & 1 & 3 & 1 & 1 & 2 & 3 & 2 & 2 & 3 & 2 \\
\hline D17S1828 & 4016949 & 3 & 4 & 3 & 4 & 3 & 3 & 4 & 3 & 1 & 1 & 4 & 1 & 1 & 1 & 4 & 6 & 1 & 6 \\
\hline D17S1876 & 4551611 & 4 & 3 & 3 & 3 & 3 & 3 & 1 & 2 & 5 & 4 & 1 & 5 & 8 & 3 & 8 & 6 & 3 & 6 \\
\hline D17S1810 & 5229472 & 6 & 2 & 1 & 1 & 2 & 1 & 1 & 2 & 3 & 1 & 1 & 3 & 4 & 1 & 1 & 1 & 1 & 1 \\
\hline D17S1832 & 6173140 & 6 & 7 & 4 & 4 & 7 & 4 & 4 & 4 & 8 & 1 & 4 & 8 & 3 & 3 & 5 & 3 & 3 & 3 \\
\hline D17S938 & 6449833 & 1 & 2 & 3 & 3 & 2 & 3 & 3 & 5 & 3 & 2 & 3 & 3 & 2 & 7 & 5 & 2 & 7 & 2 \\
\hline D17S796 & 6452087 & 7 & 1 & 5 & 5 & 1 & 5 & 2 & 3 & 1 & 4 & 2 & 1 & 1 & 6 & 3 & 4 & 6 & 4 \\
\hline \multicolumn{2}{|c|}{ CTL recognition ${ }^{C}$} & \multicolumn{2}{|c|}{+} & \multicolumn{2}{|c|}{+} & \multicolumn{2}{|c|}{+} & \multicolumn{2}{|c|}{-} & \multicolumn{2}{|c|}{ t } & \multicolumn{2}{|c|}{+} & \multicolumn{2}{|c|}{+} & \multicolumn{2}{|c|}{ - } & \multicolumn{2}{|c|}{-} \\
\hline
\end{tabular}

AThe genotypes are arranged by haplotype, with the paternally and maternally inherited haplotypes on the left and right, respectively. The haplotypes carrying the $\mathrm{LRH}-1-$ positive phenotype are shown in red and blue. Their $\mathrm{LRH}-1-$ negative counterparts are indicated in green. 0 indicates that the genotype was not available in the CEPH database. Recombinant haplotypes of individuals 102-13182, 1332-4889, and 1362-8564 are represented by 2 different colors. Recombination events in these individuals point out that the region within which the LRH-1 locus resides is defined by the flanking markers $\mathrm{D} 17 \mathrm{~S} 1845$ and D17S1876, indicated by line spaces. BGenetic markers available in the CEPH database are positioned according to the physical chromosomal map in the UCSC Genome Bioinformatics database (July 2003 freeze). ${ }^{C}$ Recognition of EBV-LCLs of each individual by CTL RP1.

from parental individuals of 13 Centre d'Etude du Polymorphism Humain (CEPH) families (provided by P. Martin, Fred Hutchinson Cancer Research Center, Seattle, Washington, USA) were transduced with HLA-B*0702 and tested for CTL RP1 recognition. Six CEPH families (i.e., 1331, 1332, 1347, 1362, 1413, and 102), of which either one or both parents were positive, were selected for further study. CTL RP1 recognition of HLA-B*0702-transduced EBV-LCLs from all individuals of these families yielded informative LRH-1 segregation patterns for genome-wide linkage analysis (Figure 2A). All HLA-B*0702-transduced EBV-LCLs were significantly recognized by the allo-HLA-B7-specific CTL KOR18, indicating that the HLA-restriction molecule was properly expressed (data not shown). A cluster of markers on chromosome $17 \mathrm{p} 13.2$ was significantly linked (i.e., log odds ratio [lod] scores > 3.0) to the locus encoding LRH-1 (Figure 2B). The maximum lod score obtained was 13.77 at $\theta=0.001$ for marker D17S1810. A 7.5-cM critical region of no recombination was defined between the flanking markers D17S1845 (7.19 cM) and D17S938 (14.69 cM) on the Marshfield genetic map. This region corresponds to a distance of $3.5 \mathrm{Mb}$ according to the UCSC Genome Bioinformatics database (http://genome.ucsc.edu/; ref. 27).

To narrow down the genetic region that includes the LRH-1 locus, we performed haplotype analysis using markers between D17S831 and D17S796. This analysis identified informative recombinant haplotypes in individual 13182 of family 102, individual 4889 of family 1332, and individual 8564 of family 1362 (Table 1). The recombinant paternal haplotype inherited by individual 13182 in family 102 indicated that the gene encoding LRH-1 is located telomeric to marker D17S1876. In an analogous fashion, the recombinant maternal haplotype inherited by individual 4889 in family 1332 and the recombinant paternal haplo- type inherited by individual 8564 in family 1362 implied that the LRH-1-coding gene lies centromeric to marker D17S1845. Taken together, these data indicated that the gene encoding LRH-1 is located between marker D17S1845 and D17S1876, a region of $1.64 \mathrm{Mb}$ on chromosome 17p13.2.

Identification of $\mathrm{P} 2 \mathrm{X} 5$ as the gene encoding $L R H-1$. In the region deduced from linkage analysis, we identified 30 known genes using the NCBI (http://www.ncbi.nlm.nih.gov/) and UCSC Genome Bioinformatics databases. Eleven of these genes represented members of the olfactory receptor gene family and were excluded from further analysis. For the remaining 19 candidate genes, we developed real-time quantitative PCR and determined the expression level of each candidate gene in LRH-1-positive (EBV-LCL and Raji) and LRH-1-negative cell types (monocytes and fibroblasts). Expression profiles of CTNS, P2X5, and ATP2A3 were most closely associated with the pattern of recognition by CTL RP1 (Table 2). However, the expression level of CTNS and ATP2A3 was only 2- to 3-fold lower in monocytes compared with EBV-LCL, whereas P2X5 mRNA was expressed at a 20-fold-lower level. Furthermore, P2X5 mRNA was not detected in fibroblasts. These data suggested that the P2X5 gene was the most likely candidate gene to encode LRH-1.

To confirm these results, we constructed expression plasmids encoding the P2X5 isoforms 1 and 2 using cDNA isolated from the homozygous LRH-1-positive CEPH individual 1331-8234. P2X5 isoform 2 lacks exon 3 (i.e., 24 aas) and 1 codon in exon 7. CTL RP1 efficiently recognized 293T-HLA-B*0702 cells transfected with P2X5 isoform 1, whereas isoform 2 was not recognized (Figure 3A). Both P2X5 isoforms cloned from the homozygous LRH-1-negative donor EBV-LCLs did not stimulate IFN- $\gamma$ release by CTL RP1 (Figure 3A). Furthermore, 293T-HLA-B*0702 cells transfected with a deletion construct encoding exons 1-5 of P2X5 isoform 1 


\section{Table 2}

Expression profile of candidate genes located between marker D17S1845 and D17S1876 on chromosome 17p13.2

\begin{tabular}{|c|c|c|c|c|}
\hline \multirow[b]{2}{*}{ Genes $^{A}$} & \multirow[b]{2}{*}{$\begin{array}{l}\text { Transcript } \\
\text { variant }^{B}\end{array}$} & \multicolumn{3}{|c|}{ Normalized relative gene expression $\mathrm{C}$} \\
\hline & & Raji & Monocytes & Fibroblast \\
\hline NYD-SP20 & 1 & 1.58 & 40.64 & 11.43 \\
\hline ASPA & 1 & 4.21 & 26.63 & 12.95 \\
\hline TRPV3 & 1 & 8.14 & 4.79 & 7.54 \\
\hline TRPV1 & $1-4$ & 2.51 & 2.16 & 1.11 \\
\hline CARKL & 1 & 0.50 & 1.74 & 0.20 \\
\hline CTNS & 1 & 0.72 & 0.37 & 0.21 \\
\hline$T I P-1$ & 1 & 1.54 & 3.43 & 6.66 \\
\hline MGC2963 & 1 & 2.68 & 3.46 & 0.70 \\
\hline$P 2 \times 5$ & $1-2$ & 2.75 & 0.05 & $<0.01$ \\
\hline ITGAE & 1 & 29.45 & 13.27 & 2.02 \\
\hline GSG2 & 1 & 4.10 & 19.09 & 4.13 \\
\hline HSA277841 & 1 & 3.17 & 9.55 & 6.73 \\
\hline \multirow[t]{2}{*}{ CAMKK1 } & $1-2$ & 0.67 & 4.58 & 0.49 \\
\hline & 3 & 9.48 & 38.05 & 3.51 \\
\hline$P 2 X 1$ & 1 & 0.07 & 8.66 & 0.23 \\
\hline ATP2A3 & $1-7$ & 0.73 & 0.47 & 0.05 \\
\hline ZZEF1 & 1 & 7.84 & 85.63 & 2.50 \\
\hline MGC32124 & 1 & 0.91 & 0.79 & 0.82 \\
\hline \multirow[t]{2}{*}{ ANKFY1 } & 1 & 0.94 & 1.17 & 0.38 \\
\hline & 2 & 4.79 & 1.91 & 0.90 \\
\hline UBE2G1 & $1-2$ & 3.12 & 8.66 & 3.62 \\
\hline \multicolumn{2}{|c|}{ CTL recognition ${ }^{\mathrm{D}}$} & + & _- & - \\
\hline
\end{tabular}

${ }^{\mathrm{A} G e n e s}$ retrieved from the NCBI database (Build 34) and the UCSC Genome Bioinformatics database (July 2003 freeze). Olfactory receptor genes are not listed. BRNA transcript variants detected with 1 set of PCR primers. ${ }^{\mathrm{C}} \mathrm{Gene}$ expression profile determined by real-time quantitative PCR using the SYBR green method. The housekeeping gene Pbgd was used for normalization. The expression in each cell type was calculated relative to the expression level measured in recipient EBV-LCLs using the $\Delta \Delta \mathrm{Ct}$ method (39). ${ }^{\mathrm{D} R e c o g n i t i o n}$ of cell type by CTL RP1.

from CEPH individual 1331-8234 were efficiently recognized by CTL RP1 (Figure 3A). Collectively, these data demonstrate that the LRH-1 antigenic epitope is derived from the 24 -aa sequence encoded by exon 3 of P2X5 isoform 1 .

A single nucleotide deletion polymorphism in the P2X5 gene determines $C T L$ recognition. We searched the human genome database for previously identified polymorphisms in exon 3 of $\mathrm{P} 2 \mathrm{X} 5$ and found a cytosine deletion polymorphism in the region encoding aas 110 and 111 of P2X5 isoform 1 (Figure 3B). To determine whether this polymorphism could be involved in recognition by CTL RP1, we sequenced and compared the P2X 5 exon 3 sequence ( $72 \mathrm{bp}$ in length) from the homozygous LRH-1-negative donor EBV-LCL and the homozygous LRH-1-positive EBV-LCL of CEPH individual 1331-8234. Interestingly, 1 cytosine nucleotide in the donor P2X5 exon 3 sequence was indeed deleted between bp 329 and 333 of the open reading frame, resulting in a frameshift at aa position 112 and a putative truncated P2X5 protein of 146 aas (Figure 3B). These results demonstrate that a single nucleotide deletion polymorphism in the P2X5 sequence controls expression of the LRH-1 antigenic epitope.

Identification of the HLA-B7-restricted LRH-1 antigenic epitope. As a result of the deletion polymorphism in exon 3, the P2X5 isoform 1 of the recipient contains a disparate NQRQNVCAE sequence com- pared with that of the donor (Figure 3B). To identify the antigenic epitope, we analyzed this disparate sequence flanked at both sides by 9 naturally occurring aas for HLA-B7-binding peptides using BIMAS prediction software. This resulted in the identification of the nonamer peptide TPNQRQNVC and the decamer peptide TPNQRQNVCA, which both have a predicted BIMAS binding score of 2.0. We synthesized these peptides and tested their ability to stimulate IFN- $\gamma$ release by CTL RP1 upon loading on donor EBV-LCL at various concentrations. Both peptides were efficiently recognized by CTL RP1 (Figure 3C). However, half-maximal IFN- $\gamma$ release for the 9-mer peptide was obtained at pulsing EBV-LCL with approximately $150 \mathrm{nM}$, whereas the 10-mer peptide showed half-maximal IFN- $\gamma$ release at a concentration of approximately $350 \mathrm{nM}$, suggesting higher avidity of CTL RP1 for the 9-mer epitope. Furthermore, HLA-B7 tetramers constructed with the 9-mer peptide efficiently stained CTL RP1, whereas HLA-B7 tetramers constructed with the 10-mer peptide were negative (data not shown). To further define the minimal epitope, we tested truncated versions of the 9-mer peptide. A peptide with a deletion of the Thr aa residue at the $\mathrm{NH}_{2}$ terminus failed to sensitize donor EBV-LCLs even at very high peptide concentrations, indicating that the Thr is the $\mathrm{N}$-terminal end of the naturally processed peptide. Deletion of the Cys aa residue at the $\mathrm{COOH}$ terminus also resulted in a significant decrease in recognition (Figure 3C). Taken together, these data indicated that the 9-mer TPNQRQNVC peptide is the naturally presented epitope at the cell surface by HLA-B7 molecules that is recognized by CTL RP1.

Expansion of LRH-1-specific CD8+ T cells after DLI precedes remission of lenkemia. To detect $\mathrm{LRH}-1$-specific $\mathrm{CD}^{+} \mathrm{T}$ cells in vivo, we constructed an HLA-B7 tetramer using the 9-mer peptide TPNQRQNVC. Before DLI, tetramer ${ }^{+}$cells could not be detected $(\leq 0.01 \%)$ in the peripheral blood of CML patient UPN389 (data not shown), whereas LRH-1-specific CD8 ${ }^{+}$T cells were clearly detectable after DLI-2 (Figure 4). The PBMC sample that was used for isolation of CTL RP1 contained $0.27 \%$ of tetramer ${ }^{+}$cells among $\mathrm{CD}^{+} \mathrm{T}$ cells. This percentage increased rapidly in the peripheral blood to a peak level of $1.6 \%$ at 6 months after cessation of CsA treatment (Figure 4). At that time, $1.4 \% \mathrm{LRH}-1$-specific $\mathrm{CD} 8^{+} \mathrm{T}$ cells could also be detected in the BM (data not shown). These in vivo-expanded LRH-1-specific $\mathrm{CD}^{+} \mathrm{T}$ cells displayed the CD45RA+CCR7-CD27- cytotoxic effector phenotype, indicative of an ongoing GVL reaction (data not shown). The number of circulating tetramer ${ }^{+}$cells declined to $0.25 \%$ at 12 months but persisted at a low frequency $(0.05-0.10 \%)$ (Figure 4). Specific detection of LRH-1-specific CTLs by the tetramers was verified after in vitro stimulation of PBMC samples with peptide-pulsed donor EBV-LCLs. After 2 rounds of stimulation, tetramer ${ }^{+} \mathrm{CD}^{+} \mathrm{T}$ cells markedly increased up to $6.8 \%$ for month $3,13.9 \%$ for month 6 , $4.2 \%$ for month 12 , and $2.0 \%$ for month 38 (Figure 4 ).

Correlation of the emergence of LRH-1-specific CTLs with clinical outcome of DLI-2 revealed that the peak of tetramer ${ }^{+}$cells was followed immediately by pancytopenia and a dramatic decrease in Bcr-Abl in the peripheral blood without an increase of GVHD (Figure 5, A and B). Thereafter, the patient remained in complete cytogenetic remission for more than 2 years despite readministration of CsA to treat chronic skin GVHD. However, 4 years after DLI-2, PCR for Bcr-Abl had become substantially positive (Figure 5B). The patient was given DLI- 3 at a relatively low dose of $1 \times 10^{6} \mathrm{CD}^{+}$ cells $/ \mathrm{kg}$ body weight in order to avoid severe GVHD. The patient did not develop GVHD, and her tumor transformed into CML in accelerated phase with almost all BM cells from recipient origin 
A

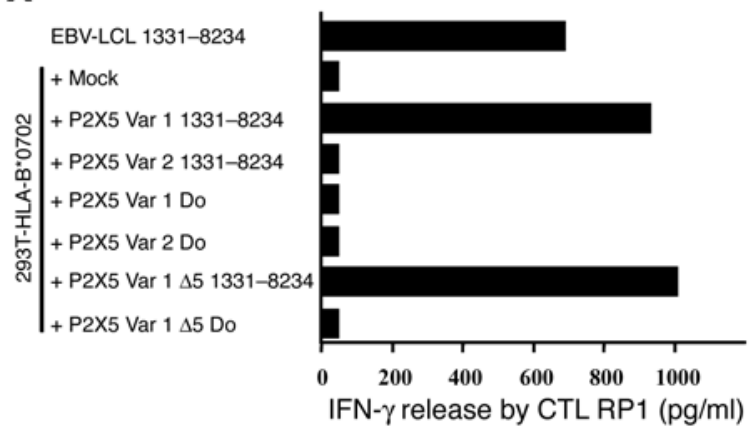

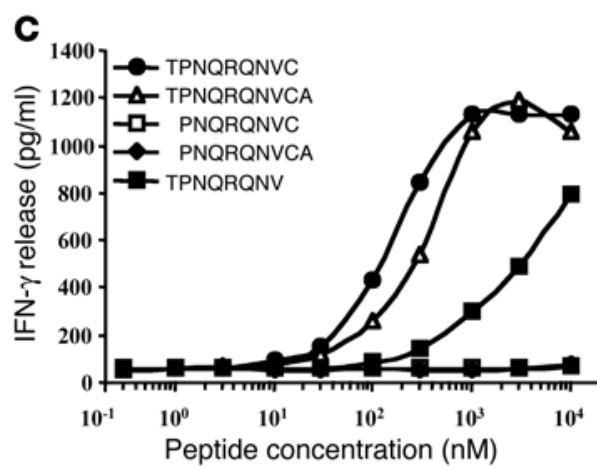

Peptide concentration (nM)

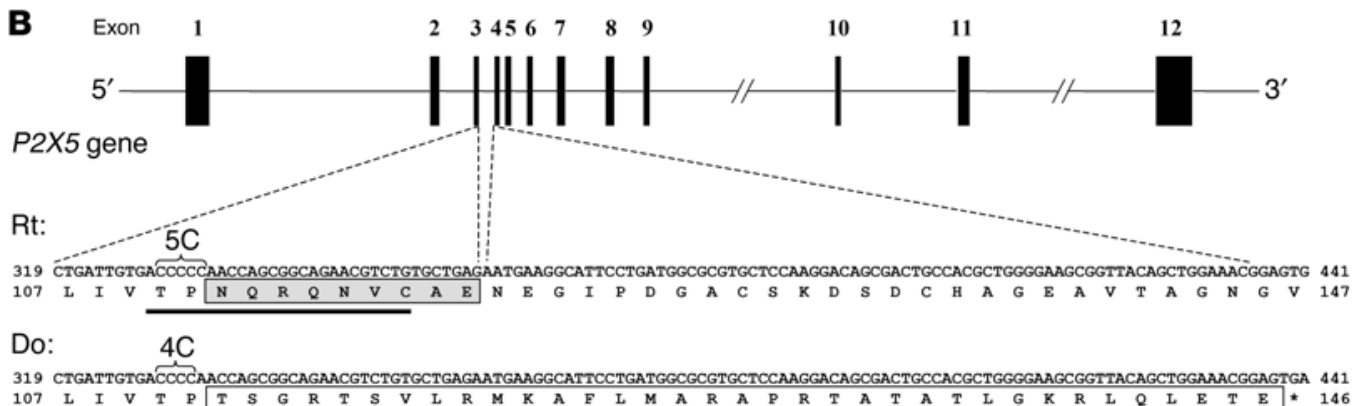

Figure 3

Identification of $P 2 X 5$ as the gene encoding the HLA-B*0702-restricted epitope $\mathrm{LRH}-1$. (A) IFN- $\gamma$ production by CTL RP1 upon stimulation with EBV-LCL from the homozygous LRH-1-positive individual 1331-8234 and 293T-HLA-B*0702 cells transfected with full-length constructs of P2X5 transcript variants 1 and 2, and deletion constructs of P2X5 transcript variant 1 encoding the first 5 exons (Var $1 \Delta 5)$ either generated from EBV-LCL of the homozygous LRH-1-positive individual 1331-8234 or the homozygous LRH-1-negative stem cell donor. (B) Schematic representation of the P2X5 gene on chromosome 17p13.2. The nucleotide and deduced aa sequences of exons 3 and 4 of both the LRH-1-positive and-negative allele present in recipient and donor, respectively, are shown. Disparity between the recipient and donor P2X5 protein sequence is due to a frameshift induced by a cytosine deletion polymorphism in the nucleotide sequence of exon 3 (5C versus $4 \mathrm{C}$ ). This results in a disparate aa sequence of 9 residues in the recipient direction (shaded box) and 35 residues in the donor direction (open box). The aa sequence of the antigenic epitope that is recognized by the HLA-B*0702-restricted CTL RP1 is underlined. (C) LRH-1 epitope reconstitution with synthetic peptides corresponding to the P2X5 exon 3 sequence of the recipient. Donor EBV-LCL was pulsed with various peptide concentrations and tested for recognition by CTL RP1. IFN- $\gamma$ production was determined by ELISA.

and with $\operatorname{del}(13)$ and $t(4 ; 11)$ as found during the first relapse. She was treated with imatinib mesylate (Glivec), and despite DLI-4 $\left(0.1 \times 10^{8} \mathrm{CD}^{+}\right.$cells $/ \mathrm{kg}$ body weight $)$ and DLI-5 $\left(0.6 \times 10^{8} \mathrm{CD}^{+}\right.$ cells/kg body weight), she entered myeloid blastic phase and died without GVHD. During this second relapse and concomitant treatment, LRH-1-specific CD8 ${ }^{+} \mathrm{T}$ cells were present but did not expand (Figure 5, A and B).

Selective expression of the $P 2 X 5$ gene in leukemic and normal CD $34^{+}$ progenitor cells, lymphoid cells, and lymphoid tissue. To more comprehensively define which cell types and tissues could be targeted by LRH-1-specific CTLs, we developed a real-time quantitative PCR that detects P2X5 transcripts encoding the LRH-1 epitope. The mean P2X5 RNA expression level compared with the reference cell line was 2.68 in EBV-LCLs, 0.28 in monocytes, and 0.10 in fibroblasts (Figure 6A). Based on our results that LRH-1-specific CTL recognizes EBV-LCLs but not monocytes and fibroblasts, we arbitrarily set the cutoff level at 0.4 to discriminate between LRH-1-positive and -negative cell types. CD $34^{+} \mathrm{CD}^{-} 8^{-}$and $\mathrm{CD} 4^{+} \mathrm{CD} 38^{+}$cells isolated from myeloid leukemias, including CML in blast crisis and acute myeloid leukemia (AML), showed significant P2X5 RNA expression levels, as well as $\mathrm{CD} 34^{+}$progenitor subsets isolated from normal BM and G-CSF-mobilized blood (Figure 6A). Interestingly, leukemic CD34+CD38- cells appear to have a significantly higher P2X5 RNA level compared with normal CD34 ${ }^{+} \mathrm{CD} 38^{-}$cells $(P=0.02$; ANOVA; Figure $6 \mathrm{~A})$. $\mathrm{CD} 34^{+} \mathrm{CD} 38^{-}$cells obtained at first relapse from CML patient UPN389 had a relatively low P2X5 RNA expression of 0.61 , whereas $\mathrm{CD} 34^{+} \mathrm{CD} 38^{+}$cells had a higher expression level of 2.67. A slightly lower P2X5 expression level of 1.31 was found in $\mathrm{CD} 34^{+} \mathrm{CD} 38^{+}$cells obtained at second relapse (data not shown). We were unable to isolate enough $\mathrm{CD} 34^{+} \mathrm{CD} 38^{-}$cells $(<5 \%$ of the total $\mathrm{CD} 34^{+}$population) from the second relapse sample. These data suggest that leukemic $\mathrm{CD} 34^{+}$progenitor subsets could be potentially targeted in vivo by LRH-1-specific CTLs.

Freshly isolated as well as cultured cells of the lymphoid lineage including B cells, EBV-LCLs, T cells, PHA-T cell blasts, and NK cells showed significant levels of P2X5 RNA expression (Figure 6B). In contrast, mature cells of the myeloid lineage including monocytes and DCs and nonhematopoietic cells including fibroblasts, keratinocytes, melanocytes, human umbilical vein endothelial cells (HUVECs), and proximal tubular epithelial cells (PTECs) had a very low level of or completely lacked P2X5 transcription. Analysis of P2X5 expression in normal tissues showed high (>1.0) transcription levels in lymphoid tissues such as spleen, tonsils, thymus, and BM (Table 3). No significant $(<0.4)$ P2X5 expression could be detected in most adult normal tissues, except 


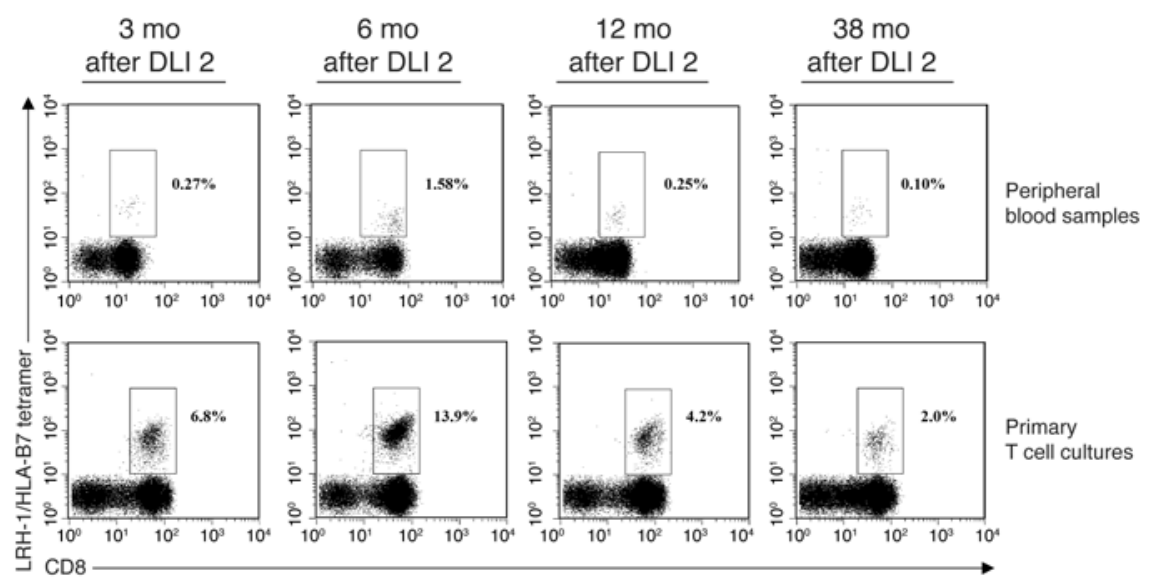

\section{Figure 4}

Detection of LRH-1-specific CD8 ${ }^{+} \mathrm{T}$ cells in peripheral blood of CML patient UPN389 after DLI. PBMCs collected 3, 6, 12, and 38 months after DLI-2 were stained with $\mathrm{LRH}-1 /$ HLA-B7 tetramer, anti-CD8, anti-CD45, antiCD3, and 7-amino-actinomycin D (7AAD). Subsequently, cell populations were analyzed by flow cytometry. Cells were gated on $\mathrm{CD}_{45}{ }^{+} \mathrm{CD} 3+7 \mathrm{AAD}-$ lymphocytes, and the percentages of tetramer-binding cells among CD8+ $\mathrm{T}$ cells are given. The remaining PBMCs were stimulated twice with $\mathrm{LRH}-1$ peptidepulsed $(10 \mu \mathrm{M})$ EBV-LCL of the donor and assayed on day 14 for $\mathrm{LRH}-1$ tetramer-binding CD8 ${ }^{+} \mathrm{T}$ cells. for low levels in neuronal and muscle tissue. Fetal brain showed a relatively high P2X5 expression level (2.80), whereas expression levels in the adult brain (0.43) and cerebellum (0.70) were much lower. Importantly, no P2X5 expression was detected in the GVHD target organs skin, liver, colon, and small intestine (Table 3). These data demonstrate that P2X5 is selectively expressed in leukemic and normal CD $34^{+}$progenitor cells and hematopoietic cells of the lymphoid lineage.

\section{Discussion}

mHAgs play a pivotal role in inducing $\mathrm{T}$ cell responses mediating GVL reactivity after HLA-identical allogeneic SCT $(4,5)$. Molecular definition of mHAg peptides is crucial for the development of immunotherapeutic protocols to either selectively boost the GVL reaction or to inhibit GVHD. In this study, we have identified a novel hematopoietic cell-restricted mHAg, designated LRH-1, which is presented by HLA-B*0702 and encoded by the $P 2 X 5$ purinergic receptor gene. CTLs specific for LRH-1 (RP1 clone) were isolated from a CML patient that was successfully treated with high-dose DLI for relapse in accelerated phase after allogeneic SCT. Here, we show a direct association between in vivo expansion of LRH-1-specific CTLs and the disappearance of Bcr-Abl-positive CML tumor cells following DLI. These findings indicate a causative role for LRH-1 in GVL reactivity. Although the patient achieved a complete cytogenetic remission after high-dose DLI, low levels of $\mathrm{Bcr}-\mathrm{Abl}$ transcripts remained detectable (Figure 5). Therefore, it remains to be investigated whether targeting of LRH-1 in patients with CML might be able to eradicate the most undifferentiated leukemic stem cells. GVHD was not increased by the emergence of LRH-1-specific CTLs despite interruption of CsA treatment. How-

\section{Figure 5}

Longitudinal follow-up of $\mathrm{LRH}-1-$ specific $\mathrm{CD} 8^{+} \mathrm{T}$ cells in peripheral blood from CML patient UPN389 in relation to clinical outcome. (A) The percentage of $\mathrm{LRH}-1$ tetramer-positive cells among $\mathrm{CD} 8^{+} \mathrm{T}$ cells (right $y$ axis) are compared with the wbc count $\times 10^{6}$ per $\mathrm{ml}$ peripheral blood (left $y$ axis). (B) The percentages of LRH-1 tetramer-positive cells among CD8 ${ }^{+} T$ cells (right $y$ axis) are compared with the relative units of Bcr-Abl in peripheral blood (left $y$ axis). The lower level of detection of Bcr-Abl PCR is $4 \times 10^{-6}$, depicted by the dotted line. Administration of DLIs 1-5 and stem cell (SC) boost are indicated by black and orange arrows, respectively. Treatment intervals with CsA and imatinib mesylate (Glivec) are shown by blue and yellow bars, respectively. ever, it is difficult to conclude that LRH-1-specific CTLs had no role in GVHD, since the patient required readministration of CsA for the treatment of chronic skin GVHD.

The level of expression of mHAgs may determine whether it is involved in GVL and/or GVHD (5). Previous studies by RNA dot blot analysis showed that P2X5 is selectively expressed in brain and lymphoid tissues (28). Here, we have used sensitive real-time quantitative PCR to determine relative expression levels of the P2X5 splice variant 1 encoding mHAg LRH-1. Our results confirm that P2X5 is highly expressed in various cell types of lymphoid origin and lymphoid tissues. Interestingly, we observed that the $P 2 X 5$ gene is significantly expressed in leukemic CD34+ subpopulations from most CML as well as AML patients. We were unable, however, to demonstrate in vitro CTL RP1 recognition of CD34+ cells of the CML patient from whom the LRH-1-specific CTL was isolated (data not shown). This may be explained by the relatively low P2X5 expression level (0.61) in the leukemic $\mathrm{CD} 34^{+} \mathrm{CD} 38^{-}$progenitor subset of this CML patient, which represented approximately $50 \%$ of the total $\mathrm{CD}_{3} 4^{+}$population (data not shown). But, P2X5 expression in vivo could be higher, result-
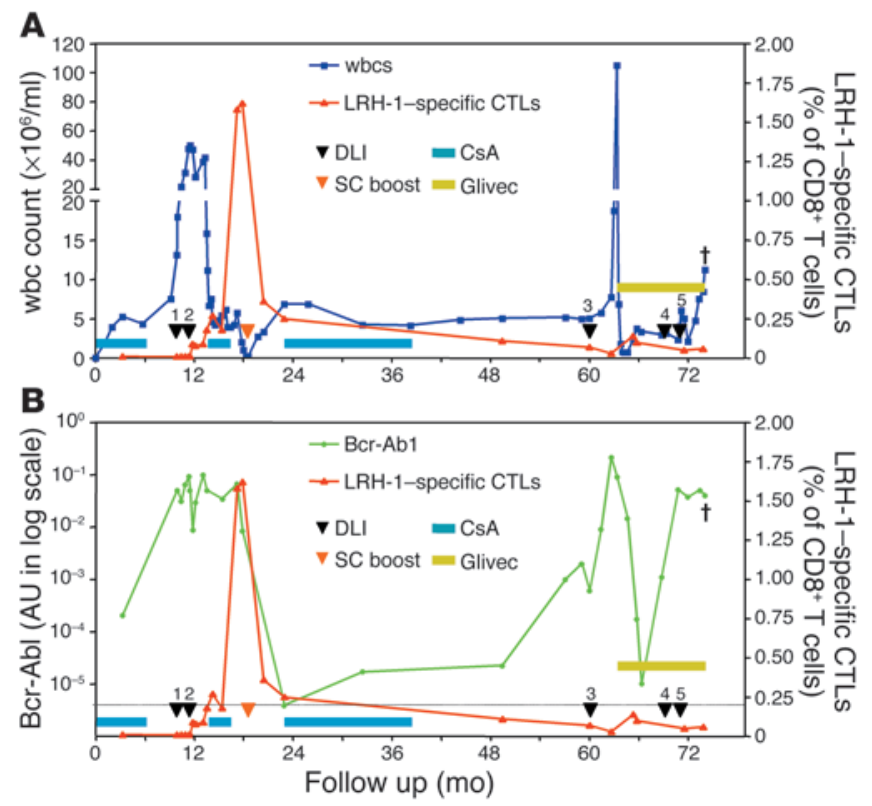

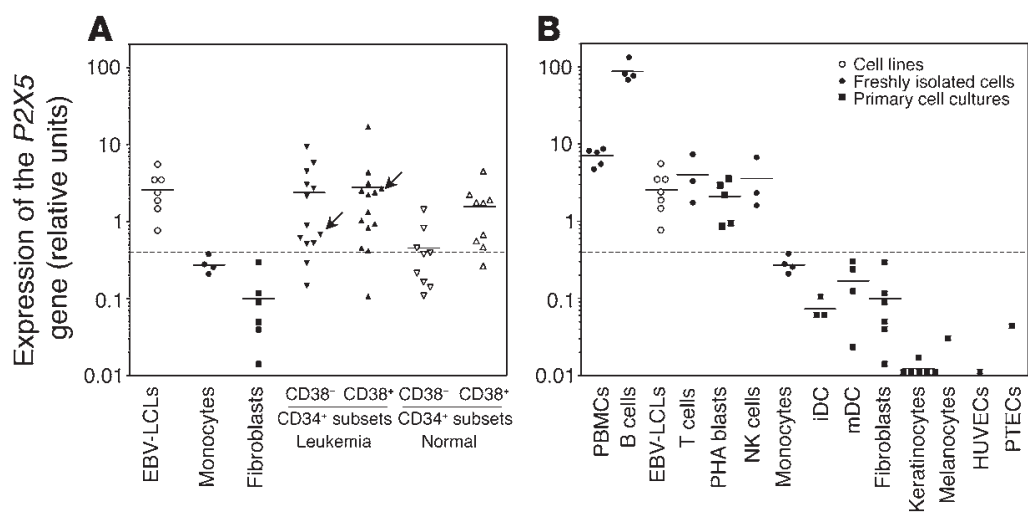

\section{Figure 6}

$P 2 X 5$ gene expression is restricted to leukemic and normal CD34+ progenitor cells as well as lymphoid cells. (A) P2X5 expression determined by real-time quantitative PCR in CD34+ subpopulations isolated from leukemia patients (CML blast crises, $n=4$ and acute myeloid leukemia, $n=10$ ) and healthy stem cell donors (normal BM, $n=4$ and G-CSF-mobilized peripheral blood, $n=5$ ). Leukemic CD34+ subsets isolated from CML patient UPN389 at first relapse are indicated by the arrows. (B) P2X5 expression determined by real-time quantitative RT-PCR in freshly isolated cells or primary cell cultures of hematopoietic and nonhematopoietic origin. Expression is shown relative to the P2X5 expression measured in the reference cell line JVM-2, which is susceptible to lysis by the LRH-1-specific CTL RP1. The housekeeping Pbgd gene was used for normalization. Cell types with $\mathrm{P} 2 \mathrm{X} 5$ expression less than 0.4 were not recognized by CTL RP1, indicating that these cell types can be considered as LRH-1 negative. This arbitrary threshold is indicated with a dashed line. The mean expression level for each cell population is shown by the thick line.

ing in increased sensitivity to CTL recognition. The efficiency of killing of leukemic CD34+ progenitor cell subsets by LRH-1-specific CTLs is currently under investigation using sensitive in vitro progenitor cell cytotoxicity assays and could be studied in vivo in the NOD/SCID leukemia model $(14,29)$.

Importantly, P2X5 is not expressed in prominent GVHD tissues such as skin, liver, colon, and small intestine. Furthermore, mature cells of myeloid origin and various nonhematopoietic cell types were negative for P2X5. In nonlymphoid tissues, we detected only high P2X5 expression levels in fetal brain, whereas in adult tissues, we observed low expression in brain, cerebellum, and skeletal muscle, which could not be explained by the presence of hematopoietic cells (Table 3). This low level of P2X5 expression could be caused by a small subset of cells present in these tissues $(30,31)$. But based on the fact that both brain and skeletal muscle are tissues that are not very likely to be infiltrated with lymphocytes without significant inflammation (32), it seemed unlikely that LRH-1-specific CTLs damage these cells in vivo. This is supported by our finding that emergence of LRH-1-specific CTLs was not accompanied by significant toxicity to these organs.

Most previously described human mHAgs result from disparities in protein sequences between donor and recipient due to nonsynonymous SNPs in their encoding genes. The resulting aa substitutions may affect either peptide processing by the proteasome (10), transporter associated with antigen processing translocation of the peptide into the ER (23), binding of the peptide to MHC (8), or recognition of the MHC-peptide complex by $\mathrm{mHAg}$-specific $\mathrm{T}$ cells $(20,22,33)$. In the case of an mHAg encoded by the UGT2B17 gene, disparity resulted from differential protein expression due to a homozygous gene deletion in the donor, although the genetic basis for this gene deletion remains to be elucidated (25). Here, we demonstrate for the first time to our knowledge that mHAgs can arise from frameshift polymorphisms that are disparate between recipients and their HLA-identical transplant donors.

$\mathrm{P} 2 \mathrm{X} 5$ is a member of the $\mathrm{P} 2 \mathrm{X}$ purinergic receptor family consisting of at least 7 proteins, $\mathrm{P} 2 \mathrm{X} 1$ to P2X7, which are capable of forming ATP-gated cation channels by homo- or heteromultimerization (34). Transcription of the human $P 2 X 5$ gene results in expression of 2 major isoforms as a result of differential splicing (28). Splice variant 1 encodes a long isoform consisting of 422 aas, whereas translation of splice variant 2 results in a shorter isoform lacking exon 3 (397 aas). Our results indicate that a donor-specific, homozygous frameshift polymorphism in exon 3 of splice variant 1 leads to the formation of a truncated aberrant version of the long P2X5 isoform. Hence, donor-derived T lymphocytes are not tolerant of the wild-type exon 3 of the recipient. The high genotype frequency (i.e., 46\%; unpublished observations) of healthy individuals that are homozygous for the cytosine deletion in exon 3 indicates that deficiency for the long P2X5 isoform is common without any significant phenotypic characteristics. The short P2X5 isoform as well as redundancy among P2X family members may compensate for the deficiency of the long P2X5 isoform.

Hematopoietic cell-restricted mHAgs are suitable targets for the application of immunotherapy to prevent or to treat recurrences of hematopoietic malignancies after allogeneic SCT. Based on its hematopoietic-specific expression, the $P 2 X 5$-encoded mHAg LRH-1 could be an attractive candidate. P2X5 is highly expressed in a broad range of lymphoid malignancies including $\mathrm{T}$ and $\mathrm{B}$ cell acute lymphoblastic leukemia, chronic lymphocytic leukemia, various types of B cell lymphoma, and multiple myeloma (unpublished observations). Furthermore, $\mathrm{CD} 34^{+} \mathrm{CD} 38^{-}$and $\mathrm{CD} 34^{+} \mathrm{CD} 38^{+}$myeloid leukemic progenitor cells were found to have enriched levels of $\mathrm{P} 2 \mathrm{X} 5$ transcripts compared with mature nonleukemic monocytes $(P<0.05$; ANOVA; Figure 6A), suggesting that LRH-1-specific CTLs may preferentially target immature myeloid leukemia cells. Therefore, vaccination with the LRH-1 peptide would be an attractive approach for induction of GVL reactivity. Recently we developed a genotyping assay for the LRH-1 mHAg, and of the 45 HLA-B7-positive SCT donors and recipients analyzed so far, 6 patients $(-13 \%)$ positive for LRH-1 mHAg received a transplant from an LRH-1-negative donor (unpublished observations). These patients would be eligible for LRH-1 peptide-based vaccination. Studies are underway to determine whether LRH-1-specific CD8 ${ }^{+} \mathrm{T}$ cells can be detected or induced ex vivo in these LRH-1 disparate transplant recipients.

In conclusion, we describe a novel hematopoietic cell-restricted mHAg, designated LRH-1, that can function as a GVL-specific antigen for hematological malignancies. The significance of mHAg LRH-1 for cellular immunotherapy of relapsed leukemia is demonstrated by the direct correlation between expansion of LRH-1-specific CTLs and disappearance of CML, and the expression of its encoding gene in leukemic $\mathrm{CD} 34^{+}$progenitor cells. In addition, we describe a novel mechanism responsible for antigenicity of $\mathrm{mHAg}$ 
Table 3

$P 2 X 5$ and $C D 45$ gene expression in normal tissues

\begin{tabular}{lccc}
$\begin{array}{l}\text { Normal } \\
\text { tissue }\end{array}$ & $\begin{array}{c}\text { P2X5 } \\
\text { expression }\end{array}$ & $\begin{array}{c}\text { CD45 } \\
\text { expression }\end{array}$ & $\begin{array}{c}\text { Ratio } \\
\text { (P2X5/CD45) }\end{array}$ \\
Adrenal gland & 0.03 & 0.21 & 0.1 \\
Bone marrow & 1.58 & 5.25 & 0.3 \\
Brain & 0.43 & 0.02 & 21.5 \\
Cerebellum & 0.70 & 0.07 & 10.0 \\
Colon & 0.12 & 0.10 & 1.2 \\
Fetal brain & 2.80 & 0.06 & 46.7 \\
Fetal liver & 0.14 & 0.14 & 1.0 \\
Heart & 0.49 & 0.28 & 1.8 \\
Kidney & 0.02 & 0.06 & 0.3 \\
Liver & 0.01 & 0.15 & $<0.1$ \\
Lung & 0.48 & 2.51 & 0.2 \\
Placenta & 0.04 & 0.99 & $<0.1$ \\
Prostate & 0.19 & 1.70 & 0.1 \\
Salivary gland & 0.37 & 0.13 & 2.8 \\
Skeletal muscle & 0.56 & 0.01 & 56.0 \\
Skin & 0.01 & 0.80 & $<0.1$ \\
Small intestine & 0.16 & 0.46 & 0.3 \\
Spinal cord & 0.35 & 0.67 & 0.5 \\
Spleen & 21.86 & 11.06 & 2.0 \\
Stomach & 0.34 & 1.47 & 0.2 \\
Testis & 0.11 & 0.09 & 1.2 \\
Thymus & 6.43 & 18.04 & 0.4 \\
Thyroid gland & 0.33 & 0.56 & 0.6 \\
Tonsils & 21.00 & 18.58 & 1.1 \\
Trachea & 0.76 & 0.78 & 1.0 \\
& & & \\
\hline Normalzed & 0.04 & \\
\hline
\end{tabular}

Normalized mRNA expression of P2X5 transcript variant 1 and CD45 was determined by real-time quantitative PCR and expressed relative to the expression level in the JVM-2 cell line.

LRH-1. Our data demonstrate for the first time to our knowledge that differential protein expression as a consequence of a homozygous frameshift polymorphism is the basis for mHAg disparity. This novel mechanism may apply to other mHAgs involved in alloresponses after HLA-identical allogeneic SCT.

\section{Methods}

Cell isolation and culture. CD8 ${ }^{+}$CTL clone RP1 was isolated from PBMCs obtained 3 months after DLI-2 by weekly stimulation with CML cells obtained at hematological relapse in Iscove's modified Dulbecco's medium (IMDM) (Invitrogen Corp.) supplemented with 10\% human serum (HS) (PAA Laboratories). Relapse CML cells that were used as stimulator cells contained $5 \% \mathrm{CD}^{2} 4^{+}$blasts, $3 \% \mathrm{CD} 19^{+} \mathrm{B}$ cells, $29 \% \mathrm{CD}^{+} \mathrm{T}$ cells, and $60 \%$ $\mathrm{CD} 13^{+} \mathrm{CD} 33^{+}$myeloid cells. Myeloid cells were completely of recipient origin, and lymphocytes were mixed chimeric. After initial stimulation, CTL RP1 $\left(0.5 \times 10^{6}\right)$ was cultured in IMDM/10\% HS containing irradiated ( $\left.80 \mathrm{~Gy}\right)$ recipient EBV-LCLs $\left(0.5 \times 10^{6}\right)$, irradiated (60 Gy) allogeneic PBMCs $\left(0.5 \times 10^{6}\right)$ from 2 donors, $100 \mathrm{IU} / \mathrm{ml} \mathrm{IL-2} \mathrm{(Eurocetus),} \mathrm{and} 1 \mu \mathrm{g} / \mathrm{ml}$ PHA-M (Boerhinger) in a total volume of $2 \mathrm{ml}$. The HLA-B7-alloreactive CTL KOR18 was kindly provided by E. Goulmy (Leiden University Medical Center). CTL KOR18 $\left(2 \times 10^{6}\right)$ was cultured in IMDM/10\% HS containing irradiated HLA-B7-positive EBV-LCLs $\left(5 \times 10^{6}\right)$, irradiated allogeneic PBMCs $\left(5 \times 10^{6}\right)$ from 2 donors, $100 \mathrm{IU} / \mathrm{ml} \mathrm{IL-2,} \mathrm{and} 1 \mu \mathrm{g} / \mathrm{ml}$ PHA-M in a total volume of $15 \mathrm{ml}$. CTL cultures were used in cytotoxicity and stimulation assays either 7 days after stimulation or 1 day after thawing a frozen aliquot. All cell lines and primary cells were cultured in IMDM/10\% FCS. EBV-LCLs from the CEPH families were provided by P. Martin (Fred Hutchinson Cancer
Research Center, Seattle, Washington, USA) or purchased from the Coriell Institute for Medical Research. B cells, T cells, and monocytes were isolated from PBMCs using anti-CD19, anti-CD3, and anti-CD14 immunomagnetic beads (Miltenyi Biotec), respectively. B cell blasts were generated by culturing CD $19^{+}$B cells in IMDM $/ 10 \%$ HS with $1 \mu \mathrm{g} / \mathrm{ml} \mathrm{CD} 40 \mathrm{~L}$ (gift from Immunex Corp.) and $100 \mathrm{U} / \mathrm{ml} \mathrm{IL-4} \mathrm{(Schering-Plough)} \mathrm{for} 5$ days. T cell blasts were generated by stimulating $\mathrm{CD}^{+} \mathrm{T}$ cells in $\mathrm{IMDM} / 10 \% \mathrm{HS}$ with $20 \mu \mathrm{g} / \mathrm{ml}$ PHA-M for 3 days. Thereafter, PHA-activated T cells were washed and further cultured with $100 \mathrm{IU} / \mathrm{ml} \mathrm{IL}-2$ for 2 additional days. Immature DCs were generated by culturing $\mathrm{CD} 14^{+}$monocytes in IMDM/5\% HS with $800 \mathrm{U} / \mathrm{ml} \mathrm{GM}$-CSF (Schering-Plough) and $500 \mathrm{U} / \mathrm{ml} \mathrm{IL-4} \mathrm{for} 6$ days. Immature DCs were maturated by culturing for 3 additional days in IMDM $/ 5 \%$ HS with $800 \mathrm{U} / \mathrm{ml} \mathrm{GM-CSF}, 500 \mathrm{U} / \mathrm{ml} \mathrm{IL-4,} 20 \mathrm{ng} / \mathrm{ml} \mathrm{TNF-} \alpha$ (Endogen), and $10 \mu \mathrm{g} / \mathrm{ml}$ Prostin $\mathrm{E}_{2}$ (Pfizer). Fibroblasts were isolated from BM aspirates of healthy stem cell donors. BM was resuspended in $20 \mathrm{ml} \mathrm{IMDM} / 20 \%$ FCS and incubated overnight in $75-\mathrm{cm}^{2}$ tissue culture flasks. The nonadherent fraction was removed, and fibroblasts were further cultured in IMDM/20\% FCS to passage 3 before analysis.

Chromium release assay. Chromium release assays were performed to assess cytolytic activity of CTLs as described previously (12). Fibroblasts were pretreated with $10 \mathrm{ng} / \mathrm{ml} \mathrm{TNF}-\alpha$ and $100 \mathrm{U} / \mathrm{ml} \mathrm{IFN}-\gamma$ (Boehringer) for 2 days before ${ }^{51} \mathrm{Cr}$ labeling. The following Abs were used for inhibition of CTL reactivity: SPV-T3b (anti-CD3), W6/32 (anti-HLA class I), B1.23.2 (anti-HLA-B/C), and SPVL-3 (anti-HLA-DQ).

Retroviral transduction of HLA-B*0702 in cell lines and CTL stimulation assay. HLA-B*0702 cDNA (provided by E. Goulmy) was subcloned in the LZRSIRES-EGFP vector. The resulting LZRS-HLA-B*0702-IRES-EGFP vector was used to generate a stable producer cell line. Retroviral transduction was performed using non-tissue culture-treated $35-\mathrm{mm}^{2}$ dishes (BD) coated with $10 \mu \mathrm{g} / \mathrm{ml}$ RetroNectin (Takara Bio Inc.). Target cells $\left(10^{6}\right)$ were resuspended in $2 \mathrm{ml}$ virus supernatant and transferred to RetroNectin-coated dishes. After 24 hours of incubation, cells were collected and incubated with fresh virus supernatant. Finally, transduced cells were cultured for 5 additional days before use in CTL stimulation assays as described previously (13). Release of IFN- $\gamma$ was determined by ELISA (Endogen; Pierce Biotechnology Inc.).

Genetic linkage analysis. Mapping of the LRH-1 locus was accomplished in a subset of CEPH reference families. Genotypes were retrieved from the CEPH database, version 9.0 (http://www.cephb.fr/cephdb/; refs. 35, 36). Two-point linkage was performed using the MLINK subroutine of the FASTLINK (version 4.0) program (http://www.cs.rice.edu/ schaffer/ fastlink.html) as reported previously $(11,36,37)$. An autosomal dominant, single gene model was assumed for the LRH-1 trait. The population frequency of the encoding allele was estimated at 0.5 and the penetrance of the LRH-1 phenotype was set at 0.9 . Population allele frequencies for the genetic markers were used when present in the CEPH database; otherwise equal allele frequencies were assumed. Resulting lod scores were examined for regions of highly significant linkage, and the identification of the LRH-1 locus was interpreted from the Marshfield genetic map (38).

Real-time PCR analysis of candidate genes. Total RNA was isolated by the TRIzol method (Invitrogen Corp.) and treated with DNase. First-strand cDNA was prepared using oligo-dT primer and Powerscript RT (BD Biosciences - Clontech). Gene-specific primer sets were designed at the $3^{\prime}$ end of each candidate gene. One microliter of cDNA was amplified in a 50- $\mu \mathrm{l}$ reaction mixture containing 1.25 U AmpliTaq Gold (Applied Biosystems), $300 \mathrm{nM}$ of each primer, $250 \mu \mathrm{M}$ of each dNTP, $5 \mathrm{mM} \mathrm{MgCl} 2$, and $1 \times$ SYBR green PCR buffer (Applied Biosystems). The porphobilinogen deaminase $(P b g d)$ gene was used to normalize expression of each candidate gene. The following primers and TaqMan probe were used for Pbgd real-time PCR: Pbgd-F 5'-GGCAATGCGGCTGCAA-3', Pbgd-R 5'-GGGTACCCACGCGAATCAC-3', and Pbgd-probe 5'-(VIC)-CTCATCTTT- 
GGGCTGTTTTCTTCCGCC-(TAMRA)-3'. Pbgd-PCR was performed as described above using $300 \mathrm{nM}$ TaqMan probe. PCR amplification was performed using an ABI Prism 7700 (Applied Biosystems) with the following PCR conditions: enzyme activation for 10 minutes at $95^{\circ} \mathrm{C}$, followed by 45 cycles of $95^{\circ} \mathrm{C}$ for 15 seconds and $60^{\circ} \mathrm{C}$ for 1 minute. The cycle threshold (Ct) was determined by software analysis (Sequence Detection System, version 1.9.1; Applied Biosystems). The expression of candidate genes was calculated using EBV-LCLs of the recipient as calibrator with the following formula: $\left[2^{-(\Delta \Delta \mathrm{Ct})}\right] \times 100(39)$.

Construction of full-length and truncated P2X5 plasmids. Constructs containing the full-length or a truncated form of the P2X5 transcript variants were generated by PCR. cDNA was prepared from a homozygous LRH-1-positive and LRH-1-negative EBV-LCLs and amplified using specific primers. The following primers were used: P2X5-FLF 5'-CATGGGGCAGGCGGG-3' and P2X5-FLR 5'-AACGTAAGCAGAGGCAATTCACGT-3'. A truncated form containing exons 1-5 of P2X5 transcript variant 1 was generated with the P2X5-FLF forward primer and reverse primer P2X5-TRR 5'-GGGGAAACGGATGTGGTTCT-3'. PCR products were purified using the QIAGEN gel extraction kit and cloned into vector pCR3 (Invitrogen Corp.) using the unidirectional TA cloning kit (Invitrogen Corp.). Plasmids (400 ng) were used for transfection into $3.5 \times 10^{4} 293 \mathrm{~T}$-HLA-B*0702 cells plated in poly-D-lysinecoated 96-well flat-bottom wells (BD) using Lipofectamine (Invitrogen Corp.). Transfected cells were cultured for 2 additional days and used in CTL stimulation assays.

Epitope prediction and reconstitution assay. HLA-B7-binding peptides were predicted using BIMAS software (http://bimas.dcrt.nih.gov/molbio/hla_ bind/; ref. 40). Peptides were synthesized by solid-phase strategies on an automated multiple peptide synthesizer (AMS 422; ABIMED). Peptides were purified by reverse-phase HPLC and lyophilized. Finally, peptides were dissolved in DMSO, diluted in IMDM to a concentration of $1 \mathrm{mM}$, and stored at $-20^{\circ} \mathrm{C}$ before use. In peptide recognition assays, target cells were preincubated with various concentrations of peptide for 30 minutes in a volume of $100 \mu \mathrm{l}$ prior to the addition of CTLs.

Tetramer staining. PE-labeled LRH-1/HLA-B7 tetramers using peptide TPNQRQNVC were produced as described previously (41). LRH-1 tetramers were validated by staining against CTL RP1. For staining, PBMC or CTL cell lines were incubated with $20 \mu \mathrm{g} / \mathrm{ml} \mathrm{LRH}-1$ tetramer for 30 minutes at room temperature. After washing with PBS/0.5\% BSA, cells were labeled with the appropriate concentration anti-CD8 (LT8-FITC; ProImmune), anti-CD3 (UCHT1-Cy7; Beckman Coulter), anti-CD45 (J33-ECD; Beckman Coulter), and $1 \mu \mathrm{g} / \mathrm{ml} 7$-amino-actinomycin D (7AAD) at room temperature for 15 minutes. After washing, cells were resuspended in PBS/0.5\% BSA and analyzed using the Coulter FC500 flow cytometer (Beckman Coulter).

Bcr-Abl PCR analysis. Bcr-Abl PCR analysis was performed on an ABI Prism 7700 system (Applied Biosystems) as described previously (42). In brief, total RNA from cells was extracted using TRIzol (Invitrogen Corp.). Reverse transcription was performed on $1 \mu \mathrm{g}$ of total RNA using random hexamers and Mo-MuLV RT (Invitrogen Corp). Expression of the Pbgd gene was used to normalize Bcr-Abl expression. This normalized Bcr-Abl expression in patient samples was related to a standard curve obtained from K562 cells diluted into normal BM cells.

Real-time quantitative PCR analysis of P2X5 gene. PBMCs were isolated from normal donors using Ficoll-Paque (Amersham Biosciences) and used for isolation of different cell subsets. PBMCs were labeled with the appropriate concentration of FITC-, PE-, and/or Cy5-conjugated Abs. Labeled cells were sorted into $\mathrm{CD} 19^{+} \mathrm{B}$ cells, $\mathrm{CD}^{+} \mathrm{T}$ cells, $\mathrm{CD}^{-} \mathrm{CD} 16 / 56^{+} \mathrm{NK}$ cells, and $\mathrm{CD} 14^{+}$monocytes using the Coulter EPICS Elite flow cytometer (Beckman Coulter). Normal and leukemic
CD $34^{+} \mathrm{CD} 38^{-}$and $\mathrm{CD} 34^{+} \mathrm{CD} 38^{+}$cells were sorted from cell suspensions after labeling with CD34-FITC and CD38-PE Abs (BD). Immature DCs, mature DCs, and fibroblasts were cultured as described above. Keratinocytes were provided by S. Ebeling (University Medical Center Utrecht, Utrecht, The Netherlands). PTECs, HUVECs, and melanocytes were provided by E. Spierings (Leiden University Medical Center). Total RNA from each of these cell types was isolated using the Zymo RNA isolation kit II (Zymo Research Corp.). RNA of normal tissues was obtained from the RNA Master Panel II (BD Biosciences - Clontech). First-strand cDNA was prepared from total RNA using oligo-dT, random hexamers, and Mo-MuLV RT (Invitrogen Corp.). In parallel to P2X5 expression, we used CD45 expression to detect the presence of hematopoietic cells in normal tissues. The Pbgd housekeeping gene was used to normalize $\mathrm{P} 2 \mathrm{X} 5$ and CD45 expression. One microliter of cDNA was amplified in a 50- $\mu 1$ reaction mixture containing 1.25 U AmpliTaq Gold (Applied Biosystems), $300 \mathrm{nM}$ gene-specific forward and reverse primer, 150-300 $\mathrm{mM}$ gene-specific TaqMan probe (150 nM for P2X5, $200 \mathrm{nM}$ for CD45, and $300 \mathrm{nM}$ for Pbgd), $250 \mu \mathrm{M}$ of each dNTP, $5 \mathrm{mM} \mathrm{MgCl}_{2}$, and $1 \times$ TaqMan PCR buffer (Applied Biosystems). The following gene-specific primers and TaqMan probes were used: P2X5: P2X5-F 5'-TCCTGGCGTACCTGGTCGT-3', P2X5-R 5'-CTTCATTCTCAGCACAGACGTTC-3', and P2X5-probe 5'-(TET)-TGGGTGTTCCTGATAAAGAAGGGTTACCA-(TAMRA)-3'; and CD45: CD45-F 5'-TTAGAAATGAGTCGCATAAGAATTGC-3', CD45-R 5'-CTCCAGGATAGTCTCCATTGTGAAA-3', and CD45-probe 5'-(TET)-ATTTCCGTGTAAAAGATC-(TAMRA)-3'. PCR conditions were as follows: enzyme activation for 10 minutes at $95^{\circ} \mathrm{C}$, followed by 45 cycles of $95^{\circ} \mathrm{C}$ for 15 seconds and $60^{\circ} \mathrm{C}$ for $1 \mathrm{~min}$ ute. P2X5 and CD45 mRNA expression was quantified by determining calibration functions using JVM-2 as reference cell line. The level of $\mathrm{P} 2 \mathrm{X} 5$ and CD45 expression of test samples was calculated relative to the P2X5 and CD45 expression in the JVM-2 cell line. P2X5 mRNA expression levels of different cell types were compared using ANOVA and Duncan post-hoc comparison. $P<0.05$ was considered significant.

\section{Acknowledgments}

We thank Hanny Fredrix, Arie Pennings (now deceased), and Gertie Vierwinden for technical assistance. We thank Ingrid Overes for CD45 PCR analysis and Shahla Abdollahi for help in LRH-1 phenotyping of LCLs. We thank Els Goulmy and Eric Spierings for providing the HLA-B*0702 cDNA, HLA-B7-alloreactive CTL KOR18, and RNA from nonmalignant cell types. We acknowledge our Molecular Diagnostics unit for performing Bcr-Abl PCR analysis. We thank Saskia Ebeling for providing RNA from keratinocytes. We thank Elke de Grouw for providing RNA of CD34+ ${ }^{+}$progenitor subsets. We acknowledge Joop Jansen and Gosse Adema for critically reading the manuscript. We thank Fred Falkenburg (Department of Hematology, Leiden University Medical Center) for advice and discussion. This work was supported by grants from the Dutch Cancer Society (KUN 2000-2294), the Bekales Foundation, the W.M. Keck Foundation, and the George S. and Delores Doré Eccles Foundation.

Received for publication February 23, 2005, and accepted in revised form September 13, 2005.

Address correspondence to: Harry Dolstra, Central Hematology Laboratory, Radboud University Nijmegen Medical Centre, Geert Grooteplein 8, PO Box 9101, 6500 HB Nijmegen, The Netherlands. Phone: 31-24-3619753; Fax: 31-24-3568408; E-mail: h.dolstra@chl.umcn.nl. 
1. Horowitz, M.M., et al. 1990. Graft-versus-leukemia reactions after bone marrow transplantation. Blood. 75:555-562.

2. Radich, J.P., Olavarria, E., and Apperley, J.F. 2004 Allogeneic hematopoietic stem cell transplantation for chronic myeloid leukemia. Hematol. Oncol. Clin. North Am. 18:685-702.

3. Sucia, S., et al. 2003. Allogeneic compared with autologous stem cell transplantation in the treatment of patients younger than 46 years with acute myeloid leukemia (AML) in first complete remission (CR1): an intention-to-treat analysis of the EORTC/ GIMEMAAML-10 trial. Blood. 102:1232-1240.

4. Goulmy, E. 1997. Human minor histocompatibility antigens: new concepts for marrow transplantation and adoptive immunotherapy. Immunol. Rev. 157:125-140.

5. Bleakley, M., and Riddell, S.R. 2004. Molecules and mechanisms of the graft-versus-leukaemia effect. Nat. Rev. Cancer. 4:371-380.

6. Marijt, W.A., et al. 2003. Hematopoiesis-restricted minor histocompatibility antigens HA-1- or HA-2 specific $\mathrm{T}$ cells can induce complete remissions of relapsed leukemia. Proc. Natl. Acad. Sci. U. S. A. 100:2742-2747.

7. Kircher, B., et al. 2002. Induction of HA-1 specific cytotoxic T-cell clones parallels the therapeutic effect of donor lymphocyte infusion. Br. J. Haematol. 17:935-939.

8. den Haan, J.M., et al. 1998. The minor histocompatibility antigen HA-1: a diallelic gene with a single amino acid polymorphism. Science. 279:1054-1057.

9. den Haan, J.M., et al. 1995. Identification of a graft versus host disease-associated human minor histocompatibility antigen. Science. 268:1476-1480.

10. Pierce, R.A., et al. 2001. The HA-2 minor histocompatibility antigen is derived from a diallelic gene encoding a novel human class I myosin protein. J. Immunol. 167:3223-3230.

11. Akatsuka, Y., et al. 2003. Identification of a polymorphic gene, BCL2A1, encoding two novel hematopoietic lineage-specific minor histocompatibility antigens. J. Exp. Med. 11:1489-1500.

12. Dolstra, H., et al. 1997. Recognition of a B cell leukemia-associated minor histocompatibility antigen by CTL. J. Immunol. 158:560-565.

13. Dolstra, H., et al. 1999. Human minor histocompatibility antigen specific for B cell acute lymphoblastic leukemia. J. Exp. Med. 189:301-308.

14. Bonnet, D., Warren, E.H., Greenberg, P.D., Dick, J.E., and Riddell, S.R. 1999. CD8(+) minor histocompatibility antigen-specific cytotoxic $\mathrm{T}$ lymphocyte clones eliminate human acute myeloid leukemia stem cells. Proc. Natl. Acad. Sci. U. S. A. 96:8639-8644.
15. Mutis, T., et al. 1999. Feasibility of immunotherapy of relapsed leukemia with ex vivo-generated cytotoxic T lymphocytes specific for hematopoietic system-restricted minor histocompatibility antigens. Blood. 93:2336-2341.

16. De Rijke, B., et al. 2003. Generation of autologous cytotoxic and helper T-cell responses against the B-cell leukemia-associated antigen HB-1: relevance for precursor B-ALL-specific immunotherapy. Blood. 102:2885-2891.

17. Wallny, H.J., and Rammensee, H.G. 1990. Identification of classical minor histocompatibility antigen as cell-derived peptide. Nature. 343:275-278.

18. Simpson, E., and Roopenian, D. 1997. Minor histocompatibility antigens. Curr. Opin. Immunol. 9:655-661.

19. Venter, J.C., et al. 2001. The sequence of the human genome. Science. 291:1304-1351.

20. Wang, W., et al. 1995. Human H-Y: a male-specific histocompatibility antigen derived from the SMCY protein. Science. 269:1588-1590.

21. Meadows, L., et al. 1997. The HLA-A*0201-restricted H-Y antigen contains a posttranslationally modified cysteine that significantly affects $\mathrm{T}$ cell recognition. Immunity. 6:273-281.

22. Pierce, R.A., et al. 1999. Cutting edge: the HLAA*0101-restricted HY minor histocompatibility antigen originates from DFFRY and contains a cysteinylated cysteine residue as identified by a novel mass spectrometric technique. J. Immunol. 163:6360-6364.

23. Brickner, A.G., et al. 2001. The immunogenicity of a new human minor histocompatibility antigen results from differential antigen processing. J. Exp. Med. 193:195-206.

24. Spierings, E., et al. 2003. The minor histocompatibility antigen HA-3 arises from differential proteasome-mediated cleavage of the lymphoid blast crisis (Lbc) oncoprotein. Blood. 102:621-629.

25. Murata, M., Warren, E.H., and Riddell, S.R. 2003. A human minor histocompatibility antigen resulting from differential expression due to a gene deletion. J. Exp. Med. 197:1279-1289.

26. Schattenberg, A., et al. 1997. Survival in first or second remission after lymphocyte-depleted transplantation for Philadelphia chromosome-positive CML in first chronic phase. Bone Marrow Transplant. 19:1205-1212.

27. Kent, W.J., et al. 2002. The human genome browser at UCSC. Genome Res. 12:996-1006.

28. Le, K.T., Paquet, M., Nouel, D., Babinski, K., and Seguela, P. 1997. Primary structure and expression of a naturally truncated human P2X ATP receptor subunit from brain and immune system. FEBS Lett. 418:195-199.
29. Jedema, I., van der Werff, N.M., Barge, R.M., Willemze, R., and Falkenburg, J.H. 2004. New CFSEbased assay to determine susceptibility to lysis by cytotoxic T cells of leukemic precursor cells within a heterogeneous target cell population. Blood. 103:2677-2682.

30. Collo, G., et al. 1996. Cloning of P2X5 and P2X6 receptors and the distribution and properties of an extended family of ATP-gated ion channels. J. Neurosci. 16:2495-2507.

31. Ryten, M., Dunn, P.M., Neary, J.T., and Burnstock, G. 2002. ATP regulates the differentiation of mammalian skeletal muscle by activation of a P2X5 receptor on satellite cells. J. Cell Biol. 158:345-355.

32. Merrill, J.E., and Benveniste, E.N. 1996. Cytokines in inflammatory brain lesions: helpful and harmful. Trends Neurosci. 19:331-338.

33. Dolstra, H., et al. 2002. Bi-directional allelic recognition of the human minor histocompatibility antigen HB-1 by cytotoxic T lymphocytes. Eur. J. Immunol. 32:2748-2758.

34. Khakh, B.S., et al. 2001. International union of pharmacology. XXIV. Current status of the nomenclature and properties of $\mathrm{P} 2 \mathrm{X}$ receptors and their subunits. Pharmacol. Rev. 53:107-118.

35. Dausset, J., et al. 1990. Centre d'etude du polymorphisme humain $(\mathrm{CEPH})$ : collaborative genetic mapping of the human genome. Genomics. 6:575-577.

36. Murray, J.C., et al. 1994. A comprehensive human linkage map with centimorgan density. Science. 265:2049-2054

37. Warren, E.H., et al. 2002. Feasibility of using genetic linkage analysis to identify the genes encoding $\mathrm{T}$ cell-defined minor histocompatibility antigens. Tissue Antigens. 59:293-303.

38. Broman, K.W., Murray, J.C., Sheffield, V.C., White, R.L., and Weber, J.L. 1998. Comprehensive human genetic maps: individual and sex-specific variation in recombination. Am. J. Hum. Genet. 63:861-689.

39. Meijerink, J., et al. 2001. A novel method to compensate for different amplification efficiencies between patient DNA samples in quantitative realtime PCR. J. Mol. Diagn. 3:55-61.

40. Parker, K.C., Bednarek, M.A., and Coligan, J.E. 1994. Scheme for ranking potential HLA-A2 binding peptides based on independent binding of individual peptide side-chains. J. Immunol. 152:163-175.

41. Burrows, S.R., et al. 2000. Peptide-MHC class I tetrameric complexes display exquisite ligand specificity. J. Immunol. 165:6229-6234.

42. Mensink, E., et al. 1998. Quantitation of minimal residual disease in Philadelphia chromosome positive chronic myeloid leukaemia patients using real-time quantitative RT-PCR. Br. J. Haematol. 102:768-774. 